\title{
Minors and Informed Consent: A Comparative Approach ${ }^{1}$
}

\author{
Loes Stultiëns, Tom Goffin, Pascal Borry, Kris Dierickx, Herman Nys \\ Centre for Biomedical Ethics and Law, Catholic University Leuven
}

\begin{abstract}
The European Convention on Human Rights and Biomedicine of the Council of Europe provides in article 6 for special protection of persons who are not able to give free and informed consent to an intervention in the health field, e.g. minors. According to the second paragraph of this article it is up to domestic law to decide whether and under which conditions a minor is capable of taking autonomous decisions in the health field.

In the present article an overview is given of the legal regulations in place regarding the position of minors in a health care setting in the EU Member States that have ratified the European Convention on Human Rights and Biomedicine namely Cyprus, Czech Republic, Denmark, Estonia, Greece, Hungary, Lithuania, Portugal, Slovakia, Slovenia and Spain. As the overview will show, the legal position of minor patients in a health care setting varies from country to country. This in view of the system they have opted for as well as the age and circumstances under which minors are allowed to take health care decisions autonomously.
\end{abstract}

\section{Keywords}

Minors; informed consent; European Convention on Human Rights and Biomedicine

\section{Introduction}

It is a well-known rule of biomedical ethics that biomedical treatment may only be carried out after a patient has been informed of the purpose, nature, risks and consequences of the intervention, and has freely consented to it. ${ }^{2}$ Article 5 of the European Convention on Human Rights and Biomedicine of the Council of Europe (hereafter the Convention) contains a general provision related to this need of informed consent prior to any biomedical intervention. However, there are individuals who are not able to exercise their right to autonomy in a health care setting due to their age (minors) or their mental capacity. In this article we would like to focus on the position of minors in a health care setting.

\footnotetext{
1) Please note that in this article we have only used "he/him" (unless it concerns a specific quotation), but of course it should also be read as "she/her".

2) R. Andorno, "The Oviedo Convention: a European framework at the intersection of human rights and health law", Journal of International Biotechnology Law, 2005, 138.
} 
The Convention contains a specific provision - article 6 - related to the protection of persons who are not able to consent. An intervention on such persons may only be carried out for their direct benefit [art. $6 \$ 1$ ]. Paragraph 2 of this article furthermore stipulates: "Where, according to law, a minor does not have the capacity to consent to an intervention, the intervention may only be carried out with the authorisation of his or her representative or an authority or a person or body provided for by law. The opinion of the minor shall be taken into consideration as an increasingly determining factor in proportion to his or her age and degree of maturity." According to the Explanatory Report to the Convention it is not the purpose of the Convention to introduce a single system for the whole of Europe. This is the reason why in the text of article $6 \$ 2$ reference is made to domestic law: it is up to each country to determine in domestic law whether or not persons are capable of consenting to a health care intervention taking account of the need to deprive persons of their capacity for autonomy only where it is necessary in their best interests. ${ }^{3}$ In view of the preservation of the autonomy of persons with regard to interventions affecting their health, the Explanatory Report furthermore states that "in certain situations which take account of the nature and seriousness of the intervention as well as the minor's age and ability to understand, the minor's opinion should increasingly carry more weight in the final decision". According to the Report in some cases it could therefore even be concluded that the consent of a minor should be necessary, or at least sufficient for some interventions. In this respect reference is made to article 12 of the United Nations Convention on the Rights of the Child, which stipulates that "States Parties shall assure the child, who is capable of forming his or her own views the right to express those views freely in all matters affecting the child, the views of the child being given due weight in accordance with the age and maturity of the child". ${ }^{4}$

The aim of this article is to provide a comparative overview of the legal position of minor patients with respect to interventions in the health field in the EU Member States which have ratified the Convention. Up till present 11 (of the at the moment of writing - 25) EU Member States have ratified the Convention: Cyprus, Czech Republic, Denmark, Estonia, Greece, Hungary, Lithuania, Portugal, Slovakia, Slovenia and Spain.

As domestic law decides whether and under which conditions a minor is capable of taking autonomous decisions in the health field, it is interesting to investigate what the legal position is of minors within the ratifying Member States. In general, legal majority is fixed at eighteen years, but — as we will see below - in certain countries minors are allowed to take autonomous decisions regarding health care issues at a younger age. We call this the age of medical majority that is

\footnotetext{
3) See $\$ 42$ of the Explanatory Report to the Convention.
}

4) See $\$ 45$ of the Explanatory Report to the Convention. 
lower than the age of legal majority. Anyhow, according to article $6 ₫ 2$ of the Convention it is required that the opinion of minors who do not (yet) have the capacity to consent to an intervention, shall be taken into consideration as an increasingly determining factor in proportion to their age and degree of maturity.

\section{The Legal Position of Minors Related to Health Care Interventions in the 11 Ratifying EU Member States}

The information provided below on the legal position of minors related to health care interventions in the 11 ratifying EU Member States is based on the one hand on the results from literature research and the investigation of existing laws and jurisprudence in those countries and on the other hand on the information retrieved from contact persons in each of them either in a university setting and/ or in public administration (Ministry of Health/Social Affairs). Information from these contact persons will be referred to as "personal communication".

\subsection{Cyprus}

The Convention, which according to article 169 (3) of the Constitution of Cyprus has superior force, entered into force in Cyprus on 1 July 2002. In 2005 Cyprus has approved a law on the Safeguarding and the Protection of the Rights of Patients (Law 1 (I) 2005). Article 11 of this law relates to informed consent and states that consent is a "prerequisite for the provision of health care" and should be preceded by "complete medical information". Article 13 (3) deals with the position of minors in relation to the provision of health care: "Where, according to the law, a minor does not have the capacity to consent to his receiving health care, health care may only be provided with the authorization of his parent or another person, who according to the law may provide such authorization [...] Provided that the opinion of the minor shall be taken into consideration as an increasingly determining factor in proportion to his age and degree of maturity".

In the case where a health care intervention is urgently needed and it is not possible to obtain in time the consent of the legal representative of a minor, such intervention may be provided unless it is obvious that the legal representative would have refused. Also in this case, the opinion of the minor must be taken into consideration as an increasingly determining factor in proportion to his age and degree of maturity [combined reading of art. 13 (2) and (3)]. In case the legal representative of a minor refuses to give consent, the matter will be referred to a court unless it concerns a medical emergency. In that case the health care provider shall act in his judgement to the patient's best interest [art. 13 (4)]. These words seem to imply an obligation to deviate from the refusal of the parent in an emergency situation if according to the opinion of the physician the treatment is in the best interest of the minor. 
In Cyprus there seems to be no possibility for a minor to decide on his own on health issues related to him, at least not under article 13. This could also be deduced from the title of this article as it reads: "Health care without the consent of the patient". However, the opinion of the minor must be taken into account (see above).

\subsection{Czech Republic}

On 1 October 2001 the Convention entered into force in the Czech Republic. According to article 10 of the Czech Constitution the Convention has superior force. Basic patient rights are laid down in a law which dates back to 1966: Act No 20/1966 on Health Care.

Article 23 of this Health Care Act relates to informed consent: (1) "A doctor must instruct a patient or members of his family in an appropriate manner about the character of the disease and necessary treatment in order to become active co-operators in medical care"; (2) "Examinations and treatment are implemented with a patient's agreement or if such an agreement can be presupposed [...]". Article 23 (3) furthermore stipulates that "If an examination or operation is necessary for the saving of a child's or a legally disabled person's life or health and parents or a guardian refuse to agree with it, an attending physician has the right to decide on it by himself. This provision relates to children who can not estimate the necessity of such an examination or operation because of their immaturity." According to Prudil the term "child" used in this paragraph is normally interpreted as concerning children below 18 years. However, problems exist regarding the position of minors in the age category of $15-18$ years. ${ }^{5}$

According to Souckova "Generally, a natural person's legal competency shall be governed by the Civil Code. The competency to obtain rights through one's own legal deeds, as well as to assume obligations, is in full extent reached at the lawful age, i.e. at the age of eighteen. Before this age, lawful age may only be reached through marriage. Minors are only competent to such legal deeds which are in their nature adequate to their intellectual and volitional maturity corresponding to their age." This rule can be found in article 9 of the Czech Civil Code and is also applicable to minors' decisions concerning health care. Their ability to decide depends not only on their maturity but also on the seriousness of the medical intervention. ${ }^{7}$ An example of the correlation between the age/maturity of a minor and the seriousness of a medical intervention can be found in a statement by the Czech Ombudsman related to compulsory vaccination: "By law, those registered as permanent residents of the Czech Republic and foreigners with long-term res-

\footnotetext{
5) Personal communication of L. Prudil.

6) K. Souckova, National regulations on Ethics and Research in Czech Republic, 2003, 12. See also the Czech Civil Code articles 8 and 9: http://mujweb.cz/www/vaske/obcan1.htm.

7) Personal communication of L. Prudil.
} 
idents permits are obliged to undergo at the requested time the stipulated type of vaccination. In the case of persons under 15 the legal representative of such persons are responsible for fulfilment of their obligation to undergo regular compulsory vaccination". ${ }^{8}$ According to Nys et al. "It follows from this that minors between 15 and 18 may (have to) consent themselves to the vaccination".

Individuals who are not capable of legal acts shall be represented by their legal representatives [art. 26 Civil Code]. If a minor cannot be considered competent, consent has to be given by his parent(s) according to the Act No. 94/1963 Coll. on Family. In such a case the right to information is delegated to the parent(s) according to article $67 \mathrm{~b}$ section 12 of the Health Care Act $1966 .{ }^{10}$

In view of the above we may conclude that in the Czech Republic it should be evaluated on a case-by-case basis whether a minor is capable of consenting to an intervention in the health field in proportion to his age and degree of maturity and depending on the seriousness of the intervention. Anyhow, in case a minor is represented by his legal representative, according to article $6 \$ 2$ of the Convention, the opinion of the minor should be taken into consideration as an increasingly determining factor in proportion to his age and degree of maturity.

\subsection{Denmark}

The Convention was ratified by Parliamentary decision of 11 May 1999. The decision of the Parliament had the form of a legal statute announcing that the Convention was now part of Danish law. It entered into force on 1 December 1999. Recently the Danish parliament adopted the Health Act — Law No. 546 of 24 June 2005 - putting together different acts related to patient rights. This new act came into force on 1 January 2007.

According to $\$ 15$ (1) of the Health Act 2005 no treatment may be initiated or continued without the patient's informed consent. Informed consent means consent given on the basis of appropriate information provided by a health care provider [ $\$ 15$ (3) Health Act 2005].

In Denmark there is a fixed age limit for medical majority: a minor who has attained the age of 15 years may personally give informed consent to treatment. The person holding parental authority must also be informed and involved in the decision taken by the minor [ $\$ 17$ (1) Health Act 2005]. However, if a health care provider is of the opinion that, after an evaluation of the individual concerned, the 15-year-old patient is not capable on his own of understanding the consequences of his decision, the person holding parental authority may give informed

\footnotetext{
8) Annual Report of the Czech Ombudsman, III General Observations, 2.4. Violation of parental obligation to have their child vaccinated www.ochrance.cz/.

9) H. Nys et al., "Patient Rights in the EU. Czech Republic", European Ethical - Legal Papers $N^{\circ} 1$, Leuven 2006, 19.

10) K. Souckova, o.c., 12.
} 
consent [\$ 17 (2) Health Act 2005]. A patient who is not capable of providing consent himself must be kept informed and involved in the discussions relating to his treatment, to the extent that he is able to understand the situation with regard to treatment, provided that such involvement is not detrimental to him. Importance should be attached to the information provided by the patient, insofar as it is appropriate and relevant [ $\$ 20$ Health Act 2005]. Regarding the provision of information it is furthermore stipulated that it should be communicated in a considerate manner and be appropriate to the particular situation/individual capabilities of the patient: his age, maturity, experience, etc. [ $\$ 16$ (3) Health Act 2005].

Under the age of 15 the parents must consent to medical interventions on these children. Also in this case the minor patient must, where possible, be kept informed and involved in the discussions about his treatment and importance should be attached to the information provided by the minor, insofar as it is current and relevant [ $\$ 20$ Health Act 2005].

If a patient, who is under 15 years of age, finds himself in a situation in which he needs immediate treatment in order to survive or in order to improve his chances of survival or considerably improve the outcome of the treatment, a health care provider may begin or continue such treatment without the consent of the patient or the person holding parental authority [\$19 Health Act 2005].

\subsection{Estonia}

The Convention which, according to article 123 of the Constitution of the Republic of Estonia has immediately superior force to any municipal law, entered into force in Estonia on 1 June 2002. The rights and obligations of patients are laid down in the general Law of Obligations Act 2001, which regulates all contractual relationships in the economy. $\$ 766$ (1) of this act relates to the duty to inform the patient (e.g. about the state of his health, nature and purpose of health care services, etc.). With respect to the obtainment of the consent of the patient $\$ 766$ (3) stipulates: "A patient may be examined and health care services may be provided to him or her only with his or her consent".

With respect to the legal position of minors in relation to the provision of health care, the Law of Obligations Act stipulates: "In the case of a patient with restricted active legal capacity, the legal representative of the patient has the rights specified in subsections (1) and (3) of this section in so far as the patient is unable to consider the pros and cons responsibly" [ $\$ 766$ (4) Law of Obligations Act].

Apparently it should be evaluated on a case-by-case basis whether a minor patient is capable of understanding the information provided and giving consent to treatment. In case the legal representative is entitled to receive information regarding the health status of the minor patient, this patient "shall be informed of the circumstances and information specified in subsection (1) of this section to a reasonable extent" [\$ 766 (4) Law of Obligations Act]. 
In case a minor patient is considered not to be capable of taking health care decisions and his legal representative is acting on his behalf, a health care provider "shall not comply with the decision" of the legal representative if this decision appears to damage the interest of the patient [ $\$ 766$ (4) Law of Obligations Act]. This seems to imply an obligation to deviate. As no provision of the Law of Obligations Act relates to the obligation to take the opinion of the minor into consideration when taking health care decisions related to him, this should be done in accordance with article $6 \$ 2$ of the Convention. ${ }^{11}$

If in an emergency situation the legal representative cannot be reached and if the failure to provide health care services would put the life of the patient at risk or significantly damage his health, the provision of health care services is permitted without the consent of the patient if this is in the interest of the patient and corresponds to the intentions expressed by him or her earlier or to his or her presumed intentions [ $\$ 767$ (1) Law of Obligations Act].

\subsection{Greece}

The provisions of the Convention form an integral part of domestic Greek law since 1 December 1999 (the date of the entry into force of the Convention that has been ratified by Greece by law 2619/1998) and prevail over any contrary provision of the law. ${ }^{12}$ Patient rights in Greece are regulated by Law No. 2071/92 on the Modernization and Organization of the Health System, initially only addressing the rights of hospitalized patients and extended to all citizens seeking health care by article 1 of the health care reform legislation of 17 July $1997 . .^{13}$ The Act of 28 November 2005 (Act 3418/2005) on the Code of Medical Ethics is also very important for the protection of the rights of patients, especially Chapter III that deals with the relation between physician and patient. ${ }^{14}$

The issue of consent to medical treatment is regulated in article 47 sec-tion 3 of Law No. 2071/1992: "Every patient has the right to give or refuse his consent to any diagnostic or therapeutic procedure intended to be carried out on him" and article 12 of Act 3418/2005 on the Code of Medical Ethics: "(1) The physician may not perform medical activities without the preceding consent of the patient, (2) The consent may not be obtained by error, deceit, deception or violate good morals. The consent should cover the entire treatment, both its contents

\footnotetext{
11) As we have seen, $\$ 766$ (4) of the Law of Obligations Act 2001 only stipulates that information must be provided to the minor patient to a reasonable extent. It does not state that the opinion of the minor patient should be taken into consideration.

12) I. Kriari-Catranis, "Human Assisted Procreation and Human Rights - The Greek response to the felt necessities of the time", European Journal of Health Law, 2003, 272.

13) K. Meralou and E. Tragakes, "Development of Patients' Rights Legislation", European Journal of Health Law, 1999, 78.

14) M. Canellopoulou-Bottis, "Recent Developments in health law in Greece", European Journal of Health Law, 2006, 107-113.
} 
and its duration". Exceptions permitting medical interventions without consent should meet the following conditions:

- the intervention is considered essential in order to avoid death or serious harm to the health of the patient

- postponement of the intervention is not indicated

- it is impossible to obtain the consent of the patient or his legal representative [art. 47 Law No. 2071/1992]

In case of a minor patient, the physician is obliged to obtain the consent of a minor's legal representative as determined by the Civil and Penal Codes. Patients under the age of eighteen are regarded as a minor. ${ }^{15}$ "In the event of minors, consent must be provided jointly by the parents [art. 1510 Civil Code]. Any disagreement between the parents is resolved by a court decision; and in the event of a conflict of interest between the parents and the minor a special guardian is assigned". ${ }^{16}$

Article 12.2 of Act 3418/2005 on the Code of Medical Ethics provides in this respect: "In case of a minor patient, consent has to be given by the person bearing parental responsibility or the legal custodian. The opinion of the minor is taken into consideration if the physician is of the opinion that having regard the minor's age and mental and emotional maturity he is able to understand his health condition as well as the nature, the consequences, the results and the risks of the treatment". About the provision of information to persons who are not able to consent article 11.4 of Act 3418/2005 on the Code of Medical Ethics stipulates: "If persons are not able to give consent, the physician has to inform them as much as possible. The physician also informs the persons who are competent to give consent according to the following article".

In case the parents of a minor refuse to give consent a physician has the right to act against the patient's parents: "In the event of a case requiring urgent attention where the parents refuse to provide consent (for example if the parents are Jehova's Witnesses refusing to consent to a blood transfusion) consent may be immediately provided by the prosecutor of the district court following a request by the responsible doctor or service [art. 1534 Civil Code and art. 456/1984 Penal Code]".${ }^{17}$ See also in this respect article 12.3 of Act $3418 / 2005$ on the Code of Medical Ethics: "Exceptionally no consent is required when consent is not given by the parents of a minor and an immediate intervention is necessary in order to save the life or health of the patient".

\footnotetext{
15) K. Meralou and E. Tragakes, o.c., 76.

16) K. Meralou and E. Tragakes, o.c., 75.

17) K. Meralou and E. Tragakes, o.c., 75-76.
} 


\subsection{Hungary}

In Hungary - where according to article 7 (1) of the Constitution the Convention does not form part of the internal law system - provisions of the Convention, which entered into force in Hungary on 1 May 2002 after its ratification on 9 January 2002, have been implemented by the Health Act CLIV of 1997 which governs the rights and obligations of patients and health care workers: when the Health Act was in the process of being elaborated, the draft text of the Convention was taken into consideration. ${ }^{18}$

The right to consent to medical treatment is regulated by article 15 of the Health Act CLIV of 1997: "(1) The patient shall have a right to selfdetermination, which may only be restricted in the cases and in the ways defined by law; (2) Within the framework of exercising the right of self-determination, the patient is free to decide whether he wishes to use health care services and which procedures to consent to or to refuse in the course of using such services, taking into account the restrictions set out in article 20; (3) The patient shall have the right to be involved in the decisions concerning his examination and treatment. Apart from the exceptions defined in this Act, the performance of any health care procedure shall be subject to the patient's consent thereto granted on the basis of appropriate information, free from deceit, threats and pressure (hereinafter referred to as 'informed consent')".

With regard to minor patients ${ }^{19}$ the Health Act contains the following provisions: incompetent patients and patients with restricted legal capacity have the right to be informed in a manner that corresponds to their age and physical condition [art. 13.5 Health Act]. Article 14.1 of the Health Act stipulates that a patient has the right not to be informed. According to Sandor and Tomka the second paragraph of article 14 provides that the provisions of paragraph 1 are also applicable to minors of 16 years of age or over. ${ }^{20}$

A competent patient ("a patient with full disposing capacity") may designate a person who is entitled to exercise the right to consent and of refusal instead of him, and who is to be informed in line with article 13 in case he becomes unable to make a decision [art. 16.1 Health Act]. According to Sandor and Tomka this provision also applies in the case of minor patients who are older than 16 years of age. ${ }^{21}$ If the patient has no, or limited disposing capacity, and there is no person

\footnotetext{
18) Personal communication of J. Sandor.

19) According to section 12 (2) of Act IV of 1959 on the Civil Code persons of 18 years are of age.

20) Personal communication of J. Sandor and Z. Tomka. This version of article 14 (2) has not been reflected in the translation of the Health Act to be consulted on www.ohchr.org/english/bodies.

21) Personal communication of J. Sandor and Z. Tomka. According to Z. Tomka this rule can be found in paragraph 6 of article 16 of the Health Act. Also in this case this version of article 16 does not correspond with the translation of the Health Act to be consulted on www.ohchr.org/english/bodies which does not provide for a subsection 6 .
} 
entitled to exercise these rights, the Health Act lists in art. 16.2 the persons who in the specified order are entitled to exercise the right to consent and of refusal within the limits specified by the law (e.g. the patient's parent). In the case of contrary declarations of the persons indicated in the same line that decision has to be taken into consideration that would be the most beneficial to the health of the patient [art. 16.3 Health Act]. This means that if the parents of a minor do not agree, the most favorable decision in view of the health of the minor must be taken into account. The decision of the legal representative may only be taken after the provision of complete and detailed information about the health status of the minor, the proposed interventions, etc. and extends only to the consent to the invasive interventions proposed by the physician which may not be detrimental to the health of the patient [art. 16.4 Health Act]. The opinions of the incompetent patient and of the patient with limited legal capacity have to be considered to an extent that professionally is acceptable [art. 16.5 Health Act].

If in the case of incompetent patients and patients with restricted legal capacity the subsistence treatment or life-saving interventions are refused when the patient suffers from an illness which, considering the actual state of medicine - regardless of the appropriate medical treatment - would lead to death within a short period of time, the health care provider files an action for the consent being supplied by the court. The physician has to provide the care that is appropriate to the health of the patient until the legally binding decision of the court will arrive [art. 21 Health Act].

In view of the above it is not completely clear whether the age limit of 16 years which relates to the right not to be informed and the right to designate a person who is allowed to consent or to refuse on his behalf - could be extended to all health care decisions of the minors concerned. In other words it is not clear whether in Hungary there is a general rule of medical majority above 16 years. On the other hand, the fact that a minor of 16 years or older is allowed to designate a person who may be informed and who may consent and refuse instead of him would imply that a minor of 16 years or older is allowed to take health care decisions autonomously: if the minor in question would not possess these rights himself he could not assign them to someone else.

\subsection{Lithuania}

The Convention entered into force in Lithuania on 1 February 2002 after having been ratified on 17 October 2002. Beside the fact that - according to article 138 (3) of the Lithuanian Constitution - the Convention forms an integral part of the Lithuanian legal order, the Convention has also been implemented in several laws among which the Law on the Rights of Patients and Compensation for the Damage to their Health of 1996 and the new Civil Code of Lithuania that was adopted in 2000 and that came into effect as of 1 July 2001. Certain patient rights which are governed by the new Civil Code are similarly regulated in the 
Law on the Rights of Patients and Compensation for the Damage to their Health of 1996 that was not abrogated when the new Civil Code came into effect. ${ }^{22}$ The provisions of the Law on the Rights of Patients of 1996 are currently being harmonized with the provisions of the Civil Code, because the 1996 legislation should not provide for a different, less-favourable regulation for individuals than the Civil Code. ${ }^{23}$

Both article 8 of the Law on the Rights of Patients and Compensation for the Damage to their Health of 1996 and article 6.729 of the Civil Code relate to consent to treatment. According to article 8.1 of the Law on the Rights of Patients "A patient may not be treated or be provided any other health or nursing care against his will, if it shall not be otherwise established by the laws of the Republic of Lithuania. If the possibility exists, the patient must be offered other treatment or other health care services". The Civil Code contains a similar provision: "The patient may not be treated or be provided any other healthcare and/ or nursing against his will, unless otherwise established by legislation [...]" [paragraph 1 of art. 6.729 Civil Code].

With respect to the legal position of minor patients there is however a difference between the regulations in the Law on the Rights of Patients and the new Civil Code. First of all article 1 (2) of the former law stipulates that a minor is a patient of 18 years or under whereas the Civil Code explicitly states that a minor who has reached the age of 16 may consent to treatment. Indeed, article 6.726 (1) of the Civil Code stipulates: "A minor who has reached the age of 16 may in his own name enter into the contract for personal healthcare services and perform other legal actions directly related to such a contract". Thus, according to the Civil Code, medical majority exists once the minor has reached the age of $16 .{ }^{24}$ As the Civil Code is more recent than the law on the rights of patients it should take priority. See also Birmontiene in this respect: "The fact that the rights of patients are currently regulated by the Civil Code of Lithuania, should considerably belittle the significance of this law [the Law on the Rights of Patients and Compensation for the Damage to their Health of 1996]". ${ }^{25}$

If a patient has not reached the age of 16 , the health care provider must fulfil his obligations towards the parents of the minor or towards the guardian [art. 6.744 (1) Civil Code]. This will also be the case if a minor, although having

22) T. Birmontiene, "Changes in the Lithuanian Health Law and the influence of the Netherlands Civil Code", European Journal of Health Law, 2002, 386.

23) T. Birmontiene, o.c., 387-388.

24) According to the personal communication received from A. Kabisaitis, article $8 \$ 1$ of the Law on the Rights of Patients does provide for a medical majority rule as of 16 years as it reads "Patients as well as those aged between 16 and 18, may be treated or provided any other healthcare and/or nursing only with the consent of the patient." This version of article $8 \$ 1$ has not been reflected in the official translation of the Law on the Rights of Patients and Compensation for the Damage to their Health of 1996 published on the website of the Lithuanian Parliament ("Seimas") to be consulted on: http://www.lrs.lt.

25) T. Birmontiene, o.c., 393. 
reached the age of 16 years, is considered not being capable of reasonably appraising his interests [art. 6.744 (2) Civil Code]. However, if such patient objects to the provision of health care services to him (to which his parents have already given their consent) health care services may only be provided if this is necessary in order to avoid serious harm to the patient [art. 6.744 (6) Civil Code]. Patients who are younger than 16 years may not be treated or be provided any other healthcare and/or nursing against the will of at least one of the parents or their statutory representative, unless the laws provide otherwise. However, if their age and the level of development permit a correct appraisal of the condition of their health and proposed course of treatment, patients younger than 16 years may not be treated against their will unless the law provides otherwise [art. 6.729 (2) Civil Code]. Thus, according to the Civil Code, below the age of medical majority the competence of a minor in health matters should be evaluated on a case-by-case basis.

The Law on the Rights of Patients provides in this respect: "A minor patient, ${ }^{26}$ who in the opinion of the physician is capable of accurately appraising the condition of his own health, shall have the right to independently initiate and decide the treatment that has been proposed for him. Upon request by the parents or custodians of the minor patient, the treating physician must advise the legal representatives of the minor, regarding the treatment, however such information may also remain withheld, with the minor having requested this, if this might harm the interests of the minor patient considerably, if other legal acts do not establish otherwise. If the minor is hospitalised, his parents or custodians must be advised of this" [art. 6 (8) Law on the Rights of Patients] And: "A minor patient must be informed of the treatment and, with his age and level of development permitting a correct appraisal of the status of his health and proposed course of treatment (the treating physician shall decide this), the minor may not be treated against his will, unless provided otherwise by the Republic of Lithuania laws. The physician shall select the methods of treatment which shall most suit the interests of the minor" [art. 8 (2) Law on the Rights of Patients].

About the provision of information the Law on the Rights of Patients furthermore stipulates that "Information to a patient who is a minor, his parents and guardians must be furnished in a form comprehensible to them. If differences are present between the minor and his parents or guardians, the treating physician, in presenting the information, must be guided by the interests of a patient who is a minor" [article 6 (7) Law on the Rights of Patients].

In case the legal representative of a minor refuses to give consent the Law on the Rights of Patients stipulates that "Should the legal representative of a patient refuse to give his consent for treatment, which is not urgent and the treating

26) In view of the Civil Code the definition of a "minor patient" in the Law on the Rights of Patients is now to be read as not heaving reached the age of 16 . 
physician be of the opinion that the treatment being provided is in keeping with the interests of the patient, the medical ethics commission of the health care institution or the Committee for Medical Ethics of Lithuania has the right to give consent for such treatment. The administration of the health care institution or the treating physician shall have the right to appeal to this commission or committee" [art. 8 (6) Law on the Rights of Patients]. The Civil Code contains more general provisions in this respect: "The provider of personal healthcare services shall fulfil his obligations to the patient's statutory representatives as provided for in paragraphs 1 and 2 of this Article, as well as to persons listed in paragraph 3 above, provided that the fulfilment of such obligations complies with the degree of care that is expected from an honest provider of personal healthcare services [art. 6.744 (4) Civil Code]. "The person established in this section, to which the provider of personal healthcare services must discharge his obligations pursuant to paragraph 2 or 3 of this Article, must act with such care which is expected from an honest representative. In the discharge of his obligations the person must involve the patient as much as possible." [art. 6.744 (5) Civil Code].

In case of an emergency situation, medical assistance may be provided without consent of the legal representative if consent cannot be obtained in time or if the legal representative refuses to give consent. It must concern required (first aid or urgent) medical assistance which - according to the treating physician or nursing staff member - is in keeping with the interests of the patient [art. 8 (5) Law on the Rights of Patients]. The Civil Code contains the following provision regarding emergencies: "[....] the services may be provided without the consent of such person [legal representative] provided there is insufficient time to receive the consent of the said person in cases where immediate action is needed to save the life of the patient" [art. 6.745 Civil Code].

As we have seen above in Lithuania there is a fixed age limit for medical majority being 16 years. Although not (yet) explicitly stated in the Law on the Rights of Patients of 1996 this rule can be found in the newly adopted Civil Code of 2000. Minors below the age of 16 may also independently take health care decisions concerning them depending on their age and level of development enabling them to accurately appraise their situation.

\subsection{Portugal}

On the first of December of 2001 the Convention entered into force in Portugal that had ratified it on 13 August 2001. According to article 8 (1) of the Portuguese Constitution the Convention is part of the internal Portuguese legal system. According to De Oliveira "Some of the provisions of the Convention didn't bring anything new to Portuguese law as the content of those provisions was the content of some Portuguese rules which were already part of the Portuguese legal system. As a matter of fact, rules about informed consent of both competent and incompetent adults, and of children, could be found in several Portuguese laws, 
the most interesting being Articles 156 and 157 of the Portuguese Criminal Code, which punishes any treatment performed without previous consent of the patient concerned and clarifies what is the content of the so-called 'duty of information'”. ${ }^{27}$ Art. 156.2 of the Criminal Code stipulates that interventions or treatments without the consent of the patient are allowed if consent can only be obtained by means of a delay that would imply danger to life or serious injury to body or health.

Apart from the provisions in the Criminal Code, some provisions related to patient rights are laid down in the Law on Health 48/90 of 24 August 1990. With respect to the issue of informed consent we should mention article $14.1 \mathrm{~b}$ ) of this law which relates to the right to decide to take or to refuse health care, unless exceptions exist in the law and art. $14.1 \mathrm{e}$ ) which relates to the right to be informed about one's situation, the possible alternatives of treatment and the probable evolution of one's condition. ${ }^{28}$

In Portugal medical majority is fixed at fourteen years as, based on article 38.3 of the Portuguese Criminal Code, a minor of 14 years of age and more can give valid consent to medical treatment if he has the ability to fully understand what is involved in the medical treatment in question. ${ }^{29}$ In case a minor does not have the ability to consent, consent must be given by the legal guardians of the child and may only be given to promote the interests of the child as art. 1878 paragraph 1 of the Portuguese Civil Code stipulates that parents are expected, in the interests of their child, to look after all aspects of the child, particularly among other things the child's health. With respect to children who are younger than fourteen years the parents of the child have the right to consent to medical treatment.

In any case, if parents give consent to medical treatment on behalf of their children, according to article 1878 paragraph 2 of the Civil Code, the opinion of the child should be taken into account as it reads: "Children have the duty to obey their parents. The latter may, however, and depending on their children's maturity, take their opinion into consideration in relation to important family matters and grant them autonomy in the running of their own lives." ${ }^{30}$

27) G. De Oliveira, "Some improvements in the Portuguese medical law", Yearbook of European Medical Law 2005, The Institute of Medical Law, Lidingö.

28) Personal communication of P. Lobato de Faria.

29) Article 38.3 of the Portuguese Criminal Code: "Consent is effective only if it has been given by someone who is over 14 years old and has the necessary discernment to judge its meaning and range, at the moment it is given". See www.verbojuridico.net.

There is, however, a proposal pending at the Parliament to change the age limit of 14 into 16.

30) The regulation of parental responsibilities underwent alterations through the 1977 reform of the Portuguese Civil Code which established a new concept of the family and consequently of the parentchild relationship which led to the imposition of a positive duty upon parents to respect their child as is reflected in article 1878 paragraph 2 of the Portuguese Civil Code. (See: G. De Oliveira and R. Martins, "National Report - Portugal" as published on http://www2.law.uu.nl/priv/cefl/Reports/pdf2/Portugal. pdf). 
Although, in view of the above, there are specific provisions within Portuguese law which relate to informed consent and more in particular to the position of minor patients, according to De Oliveira "it would be desirable to have a special Statute concerning patient rights where the issue of capacity to consent should be ruled (similarly to Spain, France, Belgium and the Netherlands)" ${ }^{31}$

\subsection{Slovakia}

The Convention, already ratified by Slovakia on 15 January 1998, takes precedence over Slovakian national laws [art. 11 Slovak Constitution] provided that they secure a greater extent of constitutional rights and liberties. As a result of a health care reform which started in 2002, several new health care laws have been implemented in Slovakia in 2004 among which Act No. 576/2004 Coll. on Healthcare and Healthcare-related services. The rights of patients are laid down in this Act.

For health care provision an informed consent is required unless otherwise stipulated by law $[\$ 4.4$ Healthcare Act]. The "attending medical worker" is obliged to provide information (purposes, nature, impacts and risks of healthcare provision, on options of proposed procedures and on risks of refusing healthcare) to a person to whom the healthcare is to be provided or another determined person $[\$ 6.1$ (a) Healthcare Act]. If health care is to be provided to a child, information should be provided to the legal representative, tutor or foster of the under-aged child $[\$ 6.1$ (b) Healthcare Act]. According to $\$ 6.4$ of the Healthcare Act, an informed consent is a ("proven") approval where health care provision is preceded by the provision of the above information. An informed consent must be given by a) a person whom the healthcare is to be provided or b) a legal representative, if the person whom the healthcare is to be provided is unapt to give an informed consent; such a person shall participate in decision making to the highest possible extent allowed by his abilities $[\$ 6.5$ Healthcare Act]. In view of $\$ 6.5$ one may conclude that, in spite of the regulation provided for in $\$ 6.1$ (b), information should, apart from the legal representative and depending on the abilities of the minor patient, also be provided to the minor patient in order to effectuate his participation in the decision making process.

In case the legal representative of a minor patient rejects to give an informed consent, the health care provider can submit an application to a court. Awaiting the decision of the court, health care may only be provided which is necessary to save the life of the person concerned [ $\$ 6.6$ Healthcare Act].

The above information makes clear that in Slovakia, the age of medical majority is equal to the age of legal majority, being 18 years: for minors under the age of eighteen their legal representative is allowed to take medical decisions on their

31) Personal communication of G. De Oliveira and A. Pereira. 
behalf. However, in accordance with article 6.2 of the Convention, the Healthcare Act stipulates that the minor patient should, as far as possible, participate in the decision making process.

\subsection{Slovenia}

Beside the patient rights provisions in the Convention (in force since 1 December 1999 after the ratification by Slovenia of the Convention on 5 November 1998), which according to article 8 of the Slovenian Constitution has superior force in Slovenia patient rights are regulated by the Law on Health Care and Health Insurance (1992) — which is applicable to insured persons only - and the Law on Health Care Activity (1992) — applicable to all citizens. However, the latter law which regulates the organization, status and the rights and obligations of health care providers, regulates patient rights only in very general terms. ${ }^{32}$ According to Trontelj "a draft law on patient rights is being introduced in the parliamentary procedure. However, the present medical and legal practice does not differ much from the provisions in the draft law. Some of it is based on the Convention on Human Rights and Biomedicine which is legally binding and is the basis for the law". 33

According to article 47 paragraph 4 of the Law on Health Care Activity "everybody has the right to give consent for any medical intervention as well as the right to be informed, prior to the intervention, about all possible methods of diagnosing and treatment and about their consequences and effects". ${ }^{34}$ Medical intervention without prior informed consent (so-called presumed consent) is only allowed in cases of urgent intervention if the patient has been unable to consent due to his medical condition [art. 48 Law on Health Care Activity]. ${ }^{35}$

In Slovenia children are considered legally competent beyond the age of 15 [art. 47/II (11) Law on Health Care Activity], ${ }^{36}$ therefore patients who are fifteen years or older are allowed to take medical decisions autonomously. Patients younger than fifteen years are represented by their parents or guardians. ${ }^{37}$ Although Slovenian law does not state that in this case the opinion of the minor should be taken into consideration as an increasingly determining factor in proportion to his age and degree of maturity, this rule can be derived from article 6.2 of the Convention as the Convention has superior force in Slovenia. According to Tron-

\footnotetext{
32) A. Bubnov-Skoberne, "EU accession and the rights of insured persons in Slovenian public health insurance”, in, A. Den Exter (ed.), The Budapest Meeting, o.c., 51.

33) Personal communication of J. Trontelj.

34) A. Selih, "Implementation of Directive 95/46/EC in Slovenia", in D. Beyleveld et al., Implementation of the Data Protection Directive in Relation to Medical Research in Europe, Ashgate Publishing, 2004, 355. 35) A. Selih, o.c., 351.

36) J. Trontelj and D. Korosec, National Regulations on Ethics and Research in Slovenia, European Communities 2003, 10 (see: http://ec.europa.eu/research/science-society/pdf/sl_eng_lr.pdf).

37) J. Trontelj and D. Korosec, o.c., 7.
} 
telj the draft law on patient rights is explicit in this respect as it states that "The person concerned [the person not able to consent, e.g. a minor patient] has to take part in decision making to a maximum degree allowed by his/her capacity to understand and act in his/her best interest." ${ }^{38}$

\subsection{Spain}

In Spain patient rights are laid down in Basic Law 41/2002 on the Autonomy of the Patient and the Rights and Obligations with regard to Clinical Information and Documentation. This law resulted from a reform of the existing legislation on health care provoked by the ratification of the Convention by Spain on 1 September 1999. Although, according to article 96 (1) of the Spanish Constitution, the Convention — ratified by Spain on 1 September 1999 - has superior force in Spain and although some patient rights were already acknowledged by the General Health Law 14/1986, the need for a reform of the existing legislation on health care seemed necessary as many aspects of the General Health Law were in contradiction with the Convention and some of the new rights provided for in the Convention were not yet acknowledged in any legal provision. ${ }^{39}$

The right to informed consent is laid down in the second paragraph of article 2 of the patient rights law of 2002 which relates to the basic principles of the law: "All actions within the scope of health require in general the prior consent of patients or users. The consent must be obtained once the patient has received prior information and shall be given in writing in the events provided for in law." In Chapter IV of the patient rights law which relates to the "Respect for the autonomy of the patient" informed consent is dealt with in a detailed manner which, according to Requejo is a "major development in Spanish medical law". ${ }^{40}$ Article 8.1 of this chapter contains a provision similar to article 2.2. With regard to emergency situations article $9.2 \mathrm{~b}$ stipulates that physicians may conduct clinical interventions essential for the health of the patient, without having to obtain his consent when there exists an immediate serious risk for the physical or mental integrity of the patient and it is not possible to obtain his or her authorization. In this case family members or persons with a de facto relation with the patient must be consulted when circumstances so permit.

In Spain a minor who has attained the age of sixteen years or a minor who is emancipated, ${ }^{41}$ is allowed to take decisions in the field of health care concerning

\footnotetext{
38) Personal communication of J. Trontelj.

39) M. Requejo, "Legal Analysis of the Spanish Basic Law 41/2002 on the Autonomy of the Patient and the Rights and Obligations with Regard to Clinical Information and Documentation", European Journal of Health Law, 2003, 258.

40) M. Requejo, o.c., 261.

41) According to the Spanish Civil Code a minor of more than 16 years may in certain cases be emancipated and take decisions on certain issues independently. In exceptional cases emancipation may be obtained even as from the age of 14 (e.g. for reason of mariage). See: M. Requejo, o.c., 263.
} 
him autonomously. This "medical majority rule" is laid down in article $9.3 \mathrm{c}$ of the patient rights law of 2002 which stipulates: "[....] In the case of minors who are neither incapable nor incapacitated, but emancipated or have reached their sixteenth birthday, then consent by representation cannot be granted..$^{42}$ Nevertheless, in the case of action entailing serious risk, according to the judgment of the doctor, the parents shall be informed and their opinion shall be borne in mind for the taking of the appropriate decision." A recent study however showed that not only in cases of "action entailing serious risk" parents are informed: according to Pérez-Cárceles et al. despite the new patient rights law almost $20 \%$ of the doctors who responded to the survey always inform the parents of 16-18 year old patients. According to the authors this would suggest that either doctors are unaware of the new legislation or that despite it they still wish to involve parents in the health care decisions of their adolescent patients. ${ }^{43}$

If a minor of sixteen years or older is neither intellectually nor emotionally capable of understanding the scope of the intervention, consent shall be given by the legal representative of the minor after the opinion of the latter has been heard (as a general rule in cases where consent is given by the legal representative the opinion of a minor who has reached the age of twelve years should be heard - see art. 9.3 c Patient Rights Law). In addition, in cases where consent of a minor is granted by representation, this should be done in accordance with the circumstances and be in proportion to the needs that have to be attended to, at all times in favour of the patient and with respect to his personal dignity [art. 9.5 Patient Rights Law]. In accordance with article 6.3 of the Convention this article furthermore stipulates that: "To the degree possible, the patient shall participate in the decision taking during the course of the process of medical care".

According to article 9.4 of the patient rights law there are some exceptions to the rule of "legal age for health care": abortion, clinical trials and assisted reproduction are subject to specific laws and to the general regime of legal age (pursuant to article 315 of the Spanish Civil Code, the legal age in Spain is 18 years). ${ }^{44}$ Another exception can be found in article 11.1 of the patient rights law which relates to prior instructions: only persons who are of age are allowed to express their wishes through a document of prior instructions. Thus, although a minor who has attained the age of sixteen years can take actual health care decisions autonomously, he cannot take health care decisions in advance before he has attained the age of eighteen years.

\footnotetext{
42) According to M. Pérez-Cárceles et al. "[...] it is admitted that the intellectual and the emotional ability of the adolescents to understand the implications of treatment is possible and therefore their consent could be valid opinion, despite being under 16.": M. Pérez-Cárceles and others, "Primary care confidentiality for Spanish adolescents: fact or fiction?", Journal of Medical Ethics, 2006, 329.

43) M. Pérez-Cárceles et al., o.c., 332.

44) M. Requejo, o.c., 263.
} 


\subsection{Conclusions}

Our research shows that the legal position of minors in relation to the provision of health care in the 11 ratifying Member States can roughly be divided into the following four categories:

1) Lawful decision making capacity only from the age of legal majority onwards:

In three countries, namely Cyprus, Greece and Slovakia, the age as of which health care decisions may be taken autonomously is fixed at 18 years (the age of legal majority). ${ }^{45}$

2) Lawful decision making capacity below the age of legal majority, fixed at a certain age (age of medical majority):

Denmark, Portugal, Slovenia and Spain have opted for a so called "fixed age limit for medical majority": minors of a certain fixed age (below the age of legal majority) are allowed to take health care decisions autonomously. ${ }^{46}$ The age at which minor patients may take health care decisions independently from their legal representatives differs however from country to country: 14 years (Portugal), 15 years (Denmark and Slovenia) and 16 years (Spain). In Portugal there is, as mentioned earlier, a proposal pending at the Parliament to change the age limit of 14 into 16 years. ${ }^{47}$ In Spain there are some exceptions to the rule of fixed age for medical majority: in case of abortion, clinical trials, assisted reproduction and prior instructions the age limit is fixed at 18 years.

3) Lawful decision making capacity to be evaluated on a case-by-case basis, according to age and maturity:

The Czech Republic and Estonia have opted for a flexible system where it should be evaluated on a case-by-case basis whether a minor is capable, according to his age and maturity, to take health care decisions autonomously. In the Czech Republic however it is not only the maturity of the minor that is taken into consideration but also the seriousness of the medical intervention.

4) Lawful decision making capacity below the age of legal majority based on both a fixed age limit as well as an evaluation on a case-by-case basis according to age and maturity:

45) Whether Hungary also belongs to this category, with an exception in two specific cases where an age level of 16 years is applicable, is not clear.

46) We must point out that the situation with respect to Hungary is not completely clear: as we have seen above it is not clear whether the age limit of 16 years is only applicable to the right not to be informed and the right to designate a person who is allowed to consent or to refuse on his behalf or whether this age limit could be extended to other/all health care decisions of the minors concerned.

47) It goes beyond the scope of this article to investigate why in these countries one has opted for these specific age levels. 
Lithuania forms a special category where there is both a fixed age limit for medical majority, being 16 years, as well as an evaluation on a caseby-case basis with respect to patients younger than 16 years.

A schematic overview of the legal position of minor patients in relation to the provision of health care in the 11 ratifying EU Member States has been provided in the table below.

Table: The legal position of minor patients in relation to the provision of health care in the 11 ratifying EU Member States

\begin{tabular}{|c|c|c|c|}
\hline & $\begin{array}{l}\text { Fixed age limit for } \\
\text { medical majority }\end{array}$ & $\begin{array}{l}\text { Age of medical } \\
\text { majority = age of } \\
\text { legal majority }\end{array}$ & $\begin{array}{l}\text { Case-by-case } \\
\text { according to age } \\
\text { and maturity }\end{array}$ \\
\hline Cyprus & & Yes: 18 years & \\
\hline Czech Republic & & $*$ & Yes \\
\hline Denmark & Yes: 15 years & & \\
\hline Estonia & & * & Yes \\
\hline Greece & & Yes: 18 years & \\
\hline Hungary & Not clear (16 years?) & $\begin{array}{l}\text { Not clear (in general } \\
18 \text { years and only in } \\
\text { two specific cases } 16 \\
\text { years?) }\end{array}$ & \\
\hline Lithuania & Yes: 16 years & & $\begin{array}{l}\text { Yes: applicable to } \\
\text { patients younger } \\
\text { than } 16 \text { years }\end{array}$ \\
\hline Portugal & Yes: 14 years & & \\
\hline Slovakia & & Yes: 18 years & \\
\hline Slovenia & Yes: 15 years & & \\
\hline Spain & Yes: 16 years & $\begin{array}{l}\text { Yes: } 18 \text { years but } \\
\text { only in case of } \\
\text { abortion, clinical } \\
\text { trials, assisted repro- } \\
\text { duction and prior } \\
\text { instructions }\end{array}$ & \\
\hline
\end{tabular}

* In countries in which one has opted for a system where on a case-by-case basis, according to the age and maturity of the minor, it should be evaluated whether a minor is capable of taking health care decisions autonomously, it goes without saying that at the age of legal majority patients are allowed to take health care decisions autonomously. 
Apart from these differences and conformities in age levels between the ratifying Member States there are other features related to the position of minor patients in a health care setting which could be highlighted here.

\section{The Legal Position of Minor Patients and the Nature of the Medical Intervention}

The legal position of minor patients may in some countries be depending on the nature of the medical intervention.

In Spain - where minors who are 16 years or older are allowed to take health care decisions autonomously — the parents of these minors must be informed and their opinion be borne in mind in the decision taking process if, according to the physician, it concerns an action entailing serious risk. As we have seen however in practice parents are also informed in case where there is no question of "action entailing serious risk". Furthermore, in case of abortion, clinical trials and assisted reproduction a Spanish adolescent must have attained the age of 18 years before he is allowed to take decisions in these matters autonomously.

In the Czech Republic — where the decision making capacity of a minor is based on an evaluation of his age and maturity - it is also the seriousness of a medical intervention which is taken into consideration. As we have seen above, vaccinations are for instance considered as a medical intervention to which a minor between 15 and 18 may consent himself.

\section{The Legal Position/Involvement of Persons with Parental Authority}

If we look at the legal position/involvement of parents with respect to health care decisions concerning their children we have seen that in certain countries specific provisions are in place as regards the decision making capacity of one or both parents, disagreement between the parents, the involvement of parents in the decision making process, etc. In countries where no specific regulation is to be found as to the decision making capacity of one or both parents we may assume that consent of one of the parents would be sufficient, unless otherwise stipulated.

In Greece health care decisions concerning their minor children must be taken by both parents as Greek law specifically provides that in the event of minors, consent must be provided jointly by the parents and in case of disagreement between them a court decision is required. Greece is the only country where this has specifically been regulated.

In Cyprus, Estonia and Hungary however it could be deduced from the wording of the specific provisions (see $\$ 2.1,2.4$ and 2.6 above) that consent of one of the parents is sufficient as in case a minor does not have the capacity to consent health care may only be provided with the authorization of his parent or the legal representative.

According to $\$ 16$ (3) of the Hungarian Health Act in case of a disagreement between the parents of a minor, the most favourable decision in view of the health of the minor must be taken into account. The Estonian Law of Obligations Act 
stipulates that a health care provider may overrule a decision of the legal representative if the decision appears to damage the interests of the (minor) patient [\$ $766(4)]$.

In Denmark - where the age limit for medical majority is fixed at 15 years the parent(s) of a minor of 15 years or older must be informed and included in the decision taken by the minor. This means that preferably both the consent of the minor and the parent(s) is obtained, but a 15-17 year old adolescent has the final say if he and his parents do not agree. ${ }^{48}$ Only in case a 15 -year-old patient, according to the physician, is not capable to take health care decisions autonomously, the person holding parental authority may give informed consent. Apparently, consent of one of the parents is sufficient.

As we have seen above, in Spain it depends in principle on the seriousness of the risk involved in the medical intervention whether parents of children who are 16 years or older are informed and their opinion be borne in mind. But also in this case it is eventually the minor who decides about a medical intervention concerning him unless it concerns an abortion, clinical trial or assisted reproduction. In case minors of 16 years or older are neither intellectually nor emotionally capable of understanding the scope of the intervention their legal representative must give consent.

In Lithuania minor patients who are 16 years or older are allowed to take health care decisions autonomously (fixed age for medical majority). Lithuanian law does not prescribe that the parents of these minors should be involved in the decision taking process. In case a minor patient of 16 years or older is not considered being capable of taking health care decisions, his parents may consent unless the patient objects to it (but then there should be no necessity to avoid serious harm: in that case the objection of the patient may be overruled).

Minor patients who are younger than 16 years may - depending on their age and level of development - consent to treatment autonomously. It is only upon the request of the parents or custodians of these patients that the treating physician must advise them regarding the treatment of the minor. However, if the minor indicates that such information might harm his interests considerably this information may be withheld. If differences are present between the minor and his parents the treating physician must, in presenting the information, be guided by the interests of the minor patient. If the minor patient is hospitalised Lithuanian law prescribes that his parents or custodians must be advised of this.

Patients younger than 16 years who are not capable of a correct appraisal of their situation may not be treated against the will of at least one of the parents, unless the law provides otherwise.

48) H. Nys et al., "Patient Rights in the EU. Denmark", European Ethical — Legal Papers No 2, Leuven 2007,17 . 


\section{The Involvement of Minor Patients in Case they do not have the Capacity \\ to Consent}

With respect to the situation where according to domestic law a minor patient does not have the capacity to consent to an intervention, we have seen that in the majority of the 11 ratifying Member States a specific provision can be found in domestic law which stipulates that, in accordance with article $6 \$ 2$ of the Convention, the opinion of the minor should be taken into consideration. This is not the case in the Czech Republic, Estonia, Lithuania and Slovenia. In these countries, however, this obligation can directly be deduced from article $6 ₫ 2$ of the Convention.

\section{Emergency Situations}

In the ratifying Member States the following specific provisions are in place in case a health care intervention is needed in order to save the life of a minor patient where either the consent of the legal representative cannot be obtained in time or the legal representative refuses to give consent.

If in Cyprus a health care intervention is urgently needed and it is not possible to obtain in time the consent of the legal representative of a minor, such intervention may be provided unless it is obvious that the legal representative would have refused. Also in this case, the opinion of the minor must be taken into consideration as an increasingly determining factor in proportion to his age and degree of maturity [combined reading of art. 13 (2) and (3)]. If the legal representative of a minor refuses to give consent in case of a medical emergency, the health care provider shall act in his judgement to the patient's best interest [art. 13 (4)].

According to art. 23 (3) of the Czech Health Care Act an attending physician has the right to decide by himself if an examination or operation is necessary for the saving of a child's life or health and parents or a guardian refuse to agree with it.

If in Denmark a patient between 15 and 17 years old, who is temporarily or permanently unable to provide informed consent or is under the age of 15 , is in a situation where immediate treatment is essential for his survival or long term improvement of the chances for survival or significantly improved result of treatment, a health care provider may initiate or proceed with treatment without consent from the patient or the parents [ $\$ 19$ Health Act 2005].

As indicated above the Estonian Law of Obligations Act stipulates that a health care provider may overrule a decision of the legal representative if the decision appears to damage the interests of the (minor) patient $[\$ 766(4)]$. Furthermore, if in an emergency situation the legal representative cannot be reached and if the failure to provide health care services would put the life of the patient at risk or significantly damage his health, the provision of health care services is permitted without the consent of the patient if this is in the interest of the patient and corresponds to the intentions expressed by him or her earlier or to his or her presumed intentions [ $\$ 767$ (1) Law of Obligations Act]. 
In Greece medical interventions without consent are permitted in case the intervention is considered essential in order to avoid death or serious harm to the health of the patient, postponement of the intervention is not indicated and it is impossible to obtain the consent of the patient or his legal representative [art. 47 Law No. 2071/1992; see also art. 12.3 of Act 3418/2005 on the Code of Medical Ethics]. In case the parents of a minor refuse to give consent a physician has the right to act against the patient's parents: "In the event of a case requiring urgent attention where the parents refuse to provide consent, consent may be immediately provided by the prosecutor of the district court following a request by the responsible doctor or service [art. 1534 Civil Code and art. 456/1984 Penal Code]". ${ }^{49}$ See also in this respect article 12.3 of Act 3418/2005 on the Code of Medical Ethics: "Exceptionally no consent is required when consent is not given by the parents of a minor and an immediate intervention is necessary in order to save the life or health of the patient".

The Hungarian Health Act stipulates that a health care provider must obtain the consent from the court in case the subsistence treatment or life-saving interventions to incompetent patients and patients with restricted legal capacity are refused which would lead to death within a short period of time. The physician has to provide the care that is appropriate to the health of the patient until the legally binding decision of the court will arrive [art. 21 Health Act].

In Lithuania in case of an emergency situation, medical assistance may be provided without consent of the legal representative if consent cannot be obtained in time or if the legal representative refuses to give consent. It must concern required (first aid or urgent) medical assistance which - according to the treating physician or nursing staff member - is in keeping with the interests of the patient [art. 8 (5) Law on the Rights of Patients]. The Civil Code contains the following provision regarding emergencies: "[....] the services may be provided without the consent of such person [legal representative] provided if there is insufficient time to receive the consent of the said person in cases where immediate action is needed to save the life of the patient" [art. 6.745 Civil Code].

Regarding emergency situations the Slovakian Healthcare Act stipulates that informed consent is not required if it is not possible to gain an informed approval in time, but can be presumed $[\$ 6.8$ (a) Healthcare Act]. With respect to minors and emergency situations the act furthermore stipulates that in case the legal representative of a minor patient rejects to give an informed consent, the health care provider can submit an application to a court. But awaiting the decision of the court, health care may be provided which is necessary to save the life of the person concerned [ $\$ 6.6$ Healthcare Act].

The Slovenian Law on Health Care Activity only contains a very general provision regarding emergency situations which stipulates that medical intervention

49) K. Meralou and E. Tragakes, o.c., 75-76. 
without prior informed consent (so-called presumed consent) is only allowed in cases of urgent intervention if the patient has been unable to consent due to his medical condition [art. 48]. No specific provisions are in place regarding the position of the legal representative of a minor in this situation.

The same can be said about Spain and Portugal: with regard to emergency situations art. $9.2 \mathrm{~b}$ of the Spanish Patient Rights Law stipulates in general terms that physicians may conduct clinical interventions essential for the health of the patient, without having to have his consent when there exists an immediate serious risk for the physical or mental integrity of the patient and it is not possible to obtain his or her authorization. In this case family members or persons with a de facto relation with the patient must be consulted when circumstances so permit.

Art. 156.2 of the Portuguese Criminal Code stipulates that interventions or treatments without the consent of the patient are allowed if consent can only be obtained by means of a delay that would imply danger to life or serious injury to body or health.

As we have seen above, the majority of the Member States mentioned contain detailed provisions regarding the treatment of minor patients in emergency situations and the position of their legal representative. In general the treating physician may provide health care in emergency situations without consent if consent of the legal representative cannot be obtained in time or in case consent is refused and the treatment is in the patient's best interest. In Hungary and Slovakia however, in case the legal representative of a minor refuses to give consent, the health care provider must obtain consent from the court. Awaiting the court decision, the physician has to provide the care that is appropriate to the health of the patient.

In conclusion, the above information shows that - where the possibility is provided by the Convention to regulate in domestic law whether and under which conditions minors are capable of taking health care decisions autonomously - the legal position of minor patients in a health care setting really varies from country to country. This in view of the system they have opted for as well as the age and circumstances under which minors are allowed to take health care decisions autonomously.

In view of these differences one could be inclined to conclude that the influence of the Convention on the harmonization of the legal position of minors in a health care setting in the ratifying Member States is, to date, minimal. The main purpose of art. 6 of the Convention is, however, to protect persons who are not able to consent and not to introduce a single system for the whole of Europe. Therefore the requirements prescribed by the Convention in art. $6 \$ 1$ and $2-$ that where a minor does not have the capacity to consent to an intervention it may only be carried out if the intervention is for his direct benefit and upon the authorization of his representative or an authority, person or body provided for by law — are essential. Furthermore, also independent from the domestic situation, 
the Convention prescribes that in all cases "The opinion of the minor shall be taken into consideration as an increasingly determining factor in proportion to his or her age and degree of maturity". As we have seen above the majority of the 11 ratifying Member States have implemented this provision in domestic law. And in the Member States who do not have such a provision in domestic law, this requirement can directly be deduced from art. $6 \$ 2$ of the Convention.

As Andorno indicates the Convention is the first binding multilateral instrument addressing biomedical human rights issues. It contains basic norms (minimum common standards) on which there is a consensus among European countries, a solid basis for further developments. ${ }^{50}$

\section{Acknowledgement}

The research for this contribution was supported by the EuroGentest Network of Excellence of the EU, FP6-512148.

We would like to thank the following persons who provided us with information: Guilherme De Oliveira, Mette Hartlev, Kristi Louk, Andrius Kabisaitis, Peter Kovác, Ants Nomper, Dimitrios Paraskevis, Laine Peedu, André Pereira, Lukas Prudil, Mayte Requejo-Naveros, Judit Sándor, Heloísa Santos, Zsuzsanna Tomka, Joze Trontelj, Zvezdana Veber Hartman, Takis Vidalis and Rena VrahimiPetridou. 